\title{
Optimizing economic outcomes in the management of COPD
}

\author{
Roberto Dal Negro \\ Lung Dept., Orlandi General Hospital, \\ Bussolengo, Verona Italy
}

\begin{abstract}
Attention to COPD is increasing worldwide because its high prevalence, morbidity, and mortality present a challenging problem for all healthcare systems. The burden of COPD, which is usually measured in terms of progressive lung function decline, impact on patients' symptoms, patient's disability, and quality of life, together with the corresponding use of health care resources, is still a major aspect of the disease. Recommendations to treat COPD according to the most accepted guidelines have expanded in recent years even though COPD still remains unacceptably under-diagnosed and under-treated worldwide. Obviously, more severe degrees of COPD receive major attention both in terms of monitoring of clinical outcomes and of assessing the economic value of therapeutic interventions. The role of different strategies against COPD should be valued on the basis of their effectiveness in outcome optimization, which primarily depends on the efficacy of prevention activities and of early diagnosis programs. It is generally agreed that the main proportion of COPD burden still depends on the clinically uncontrolled disease and on its high exacerbation rate, which frequently leads to the patient hospitalization. In COPD, the effects of guideline recommendations have been only sporadically investigated in pharmaoeconomic terms, even though symptoms and disability have declined substantially; the corresponding improvement in quality of life, and a significant decrease in both direct and indirect costs have been proved to depend on appropriate rehabilitative and pharmacological long-term treatment of the disease. At present, more precise indices and more fitting outcomes are continuously sought and found in order to assess more effective strategies for controlling COPD.
\end{abstract}

Keywords: COPD, economic outcomes of COPD, COPD burden, COPD pharmacoeconomics

\section{Introduction}

Chronic obstructive pulmonary disease (COPD) is a disease state characterized by a not fully reversible airflow limitation which leads to a progressive functional decline, with cigarette smoking being the major risk factor (WHO 1998). Results of all epidemiological studies prove that the prevalence of respiratory symptoms is higher in smokers than in non-smokers, and that COPD prevalence increases with age (Silverman and Speizer 1996). Other factors responsible for the high prevalence and incidence of COPD are the increasing mean age of populations together with persistent and ever increasing environmental pollution (Silverman and Speizer 1996; Murray and Lopez 1997; Viegi et al 2001).

COPD is the fourth leading cause of death (Murray and Lopez 1997; WHO 1998) and one of the main causes of disability in the world, particularly in developed countries. COPD is the chronic respiratory disease that represents the most significant, and ever increasing, world-wide public health problem; its epidemiological, clinical, social, and economic impact will increase in the near future (Lee et al 2006), making it the third most important cause of death in the next 10-15 years (Murray and Lopez 1997). 
The GOLD guidelines classify disease severity in different stages based on clinical symptoms - forced expiratory volume in one second $\left(\mathrm{FEV}_{1}\right)$ and forced vital capacity (FVC). Their main goal is to increase awareness of COPD, and decrease morbidity (such as GP visits, ER visits, hospitalizations) and mortality due to the disease (GOLD 2003, 2004; Miller et al 2005).

\section{Epidemiology of costs}

Chronic respiratory diseases concern a large number of subjects and generate important health and social costs. The global impact of these diseases, in particular COPD, is the subject of an increasing number of pharmacoeconomic studies published over the last few years (Dal Negro et al 2002; Rennard et al 2002; Miller et al 2005; Chapman et al 2006).

In particular, concerns about COPD are quite recent compared with bronchial asthma (Skrepnek and Skrepnek 2004; Chapman et al 2006), and the overall impact of COPD was properly understood only a few years ago when all international scientific institutions emphasized the burden of COPD mainly due to its growing prevalence and increasingly alarming incidence (Murray and Lopez 1997; European Lung White Book 2003; Halbert et al 2003; Lee et al 2006). COPD represents an enormous health problem for the communities: patients and their families, the workplace, health institutions, and society as a whole are heavily affected by the disease (Minkoff 2005).

In general, the impact of COPD has been proven to be high in all countries, particularly in most industrialized countries.

In the US, the country that first oriented studies on COPD, the total annual cost of COPD has been estimated at nearly US\$24 billion in 1993, more than $60 \%$ of which is due to direct costs, $18 \%$ to early death, and $20 \%$ to morbidity (Sullivan et al 2000). In 2000, total annual cost of COPD in the US had increased by more than $30 \%$, reaching US $\$ 31$ billion, with a substantial increase in indirect costs (Ramsey and Sullivan 2004). A further increase was assessed in 2004 , with an estimated cost of US $\$ 37.2$ billion (National Heart, Lung, and Blood Institute 2004). COPD annual direct costs per patient depend on the clinical severity of the disease, ranging from US\$1681 for mild to US\$10,812 for severe COPD (Hilleman et al 2000).

In an Italian bottom-up study carried out on a sample of the general population corresponding to more than 5 million inhabitants and aimed to assess the cost of COPD, the mean annual cost per patient was $€ 2100$, ranging from
$€ 1500$ for milder clinical stages ( $65 \%$ of cases) to $€ 3900$ for most severe cases (5\% of cases) of COPD (Skrepnek and Skrepnek 2004).

A further nation-wide survey in 2003 based on telephone interviews, the cost was confirmed to vary as a function of clinical severity of COPD, reaching $€ 7000$ /patient/year in the most severe cases. Hospital admission has been found to account for $75 \%$ of the total cost (Dal Negro et al 2003a).

As assessed in the US and in Italy, mean annual cost of COPD has progressively increased over the last few years, increasing by $35 \%$ to reach an average of $€ 2720 /$ patient (Dal Negro et al 2008).

Direct costs for COPD were shown to be correspondingly high also in the Netherlands, where the annual cost per patient of managing COPD is almost 3 times as high as that of asthma (Rutten van Molken and Feenstra 2001; Oostenbrink et al 2004). Similar results were obtained also in France, where total medical consumption of COPD patients was $€ 3.5$ billion, which accounted for $3.5 \%$ of total medical expenditure (Detournay et al 2004). Similar results have been shown for Spain (Miravittles et al 2002; Masa et al 2004), the UK, Ireland (Tynan and Lane 2005; Halpin 2006), and Sweden (Jacobson et al 2000), thus confirming that COPD represents a common but increasing problem in all western countries, with different healthcare systems.

The impact of COPD has been assessed also in Far East countries. In Japan, the estimated total annual cost of COPD corresponded to US\$6.8 billlion, mainly due to direct costs related to most severely affected patients (mean per patient cost US\$3694) (Nishimura and Zaher 2004).

Similar data were also obtained from other studies carried out in different Asian and African countries (Chan-Yeung et al 2004).

As estimates of the economic impact of the disease are important for allocating resources, the future COPD economic impact should be estimated periodically by means of pharmacoeconomic surveys (bottom-up or top-down), or by means of health economic models in order to orient future interventional strategies with higher precision and maximize the value of resource allocation. Data from these studies suggest that the projected annual cost (US\$) for COPD in the US will increase from 176.8 to 389.2 to 832.9 billion in the next 5, 10, and 20 years, respectively (Lee et al 2006), further pinpointing the dramatic impact of COPD also for the future generations.

In all studies on pharmcoeconomics of COPD, different cost perspectives have been adopted: the patient perspective, by assessing only indirect costs (such as lost productivity 
of the patient and his/her first-degree relatives); the health service perspective, by calculating only direct costs (such as hospitalizations, medical visits and examinations, pharmaceutical treatments, rehabilitation); and the societal perspective, by taking into account both direct and indirect costs.

Data from all studies are confirming the high proportion of direct costs mainly due to hospitalizations and the increasing impact of indirect costs of COPD. Moreover, while direct costs are driven mainly by exacerbations of COPD, which represent the most important cause of hospitalization in all countries, the costs for the diagnostic and the investigational approach to the disease still represent a negligible proportion of total healthcare costs (5\%-6\% only) (Britton 2003; Dal Negro et al 2008). Furthermore, direct costs due to pharmacological treatments tend in general terms to reflect the current largely inadequate approach to and the undertreatment of COPD (Dal Negro et al 2002; Rennard et al 2002; Chapman 2006).

\section{The outcomes}

Although pharmacoeconomic studies can recognize different experimental designs, nevertheless they confirm the elevated and ever growing impact of COPD in all countries, from both the perspective of patients and their families, and of society as a whole.

The impact of COPD can be investigated by assessing and monitoring several indices which should inform on the real burden of the disease for the patient and the health care system, and provide the evidence that should contribute to improving the management of the disease at a personal and societal level.

As COPD affects the patient's life substantially even in the earliest stages, some outcomes will be related to the personal and subjective perceptions of the disease, such as symptoms, disability, and quality of life; other indicators will be related more to the patient's objective conditions which can progressively deteriorate, such as lung function, absenteeism, frequency and severity of exacerbation, number of hospital admissions, and mortality (Anto et al 2001; Viegi et al 2001; Rennard et al 2002; Miller et al 2005).

Unfortunately, as these outcomes reveal different sensitivities and prove variably related, the precise detection of COPD effects can represent an issue difficult to clarify in real life.

The subject's perception of disease severity and disease severity as indicated by specific breathlessness scales can differ significantly. It has been demonstrated that many COPD subjects tend to underestimate the severity of their condition and define as mild or moderate their dyspnea even if they scored objectively the highest levels on the Medical Research Council dyspnea scale (Rennard et al 2002). Furthermore, females rate their dyspnea higher than males despite their reduced smoking habit (Rennard et al 2002), thus confirming the intrinsic variability of this outcome.

COPD is defined as a disease condition characterized by a progressive and not fully reversible airflow limitation. Recently it has been shown that a variable proportion of COPD patients $(20 \%-40 \%)$ prove reversible in terms of lung function, even though at a different extent, and depending on the functional indicator used (Calverley et al 2003a). Moreover, the absence of reversibility, such as in terms of $\mathrm{FEV}_{1}$, does not correspond at all to a complete unresponsiveness to bronchodilators or other therapeutic strategies. Actual changes in $\mathrm{FEV}_{1}$ following bronchodilators can be small but are often accompanied by larger changes in lung volumes, which contribute to a reduction in perceived breathlessness (Celli and MacNee 2004). In these circumstances an increase in lung volume and in inspiratory capacity can represent much more fitting indicators than $\mathrm{FEV}_{1}$ for a substantial improvement in clinical signs (such as breathlessness, or exercise tolerance, or health status) as referred by the patient.

The use of only one global outcome with the aim of summarizing effectively and synthetically all events related to COPD has been more or less abandoned due to the multifactorial expression of the disease. A combination of humanistic, lung function, and clinical parameters are usually combined with measures of quality of life in order to obtain a much more fitting profile of the burden of COPD.

Obviously, survival can be regarded as the strongest outcome, but it represents an a posteriori outcome from the patient's perspective, even though it is of a great strategic value from both health care system and societal perspectives.

Other outcomes, the intermediate outcomes, are closer to the patient's belief (such as, symptom relief, absenteeism, and exacerbations), and characterized by a high prognostic value (D'Souza et al 2006). Even though a unique definition of COPD exacerbation is not yet available and widely accepted (D'Souza et al 2006), exacerbations are regarded as an important intermediate outcome from all perspectives. Their frequency and clinical severity, the time interval for a new COPD exacerbation, together with data on the amount of health resources needed for their control and data on indirect costs contribute to provide a useful method for assessing and comparing the effects of different therapeutic interventions. 
Quality adjusted life expectancy measure (Golmohammadi and Jakobs 2004) and disability adjusted life years (DALY) (Lopez and Murray 1998) are also measures used to assess the burden of COPD even though these particular outcomes are much more relevant to the most severe cases of the disease: in other words, they are regarded as particularly reliable for those patients who are more disabled and limited by COPD.

\section{Outcomes optimization}

Because of the ever growing need to reconcile the limited economic resources available with the increasing demand for well-being by the general population, health services of industrialized countries have been devoting more and more attention to the costs generated by healthcare in their own territories.

Cost of illness (COI) analysis by measuring and estimating the resources consumed in disease management is a useful methodological tool that broadens the criteria for evaluating the effects of a given disease, because it provides information about the economic (as well as clinical) effects of the disease on the entire "health system" (Ofman et al 2004).

On the basis of the epidemiological and pharmacoeconomic evidence described above, the main tools for outcomes optimization in COPD should be:

- prevention;

- early diagnosis;

- reduction in hospital costs;

- treatment of disability;

- pharmacological treatments.

\section{Prevention}

Prevention is certainly the key point of outcome optimization. It should be oriented first to the avoidance of the main disease risk factors (such as tobacco smoke). Smoking cessation is known to represent the only intervention able to delay disease progression, and programs for smoking cessation are known to be effective for COPD, but also against all other related disease (such as cardiovascular diseases and lung cancer). These programs are effective also in economic terms. A study carried out on children ( $0-12$ years) living in families with smokers and oriented to the assessment of avoidable costs, showed that smoking abatement led to a progressive and substantial amount of savings following the first and second year of the program (US\$338 and US\$991 annually per patient, respectively) (Peters et al 1998). These programs proved also cost-effective in terms of reducing mortality from all causes (Godtfredsen et al 2002a) and reducing hospital admissions (Godtfredsen et al 2002b). It should be considered that even though these programs, usually combined with specific educational programs for smoking cessation, provide only long-term results, they likely represent the only effective programs for countering the increasing prevalence of COPD in the near future and the corresponding huge increase of health care costs (Feenstra et al 2001; Lee et al 2006).

Reduction in occupational risk factors would also represent a cost-effective approach, as demonstrated a few years ago in the US: the total cost related to occupational factors ranged from US\$3.3 to 6.6 billion, comprising direct costs due to hospitalizations $(57 \%)$, and indirect costs due to morbidity (25\%) and mortality (18\%) (Leigh et al 2002).

The long-term cost-effectiveness of programs for abatement of environmental pollution is much more difficult to assess, even though the reduction in $\mathrm{NO}_{2}$ concentration to a proposed level of $25 \mathrm{ppb}$ could yield savings in mean direct out-of-pocket expenses per capita for treatment of persistent cough, persistent cough and phlegm, and wheeze in children of US\$6.80-7.90 billion, and reduce average work/school days lost per capita by 3.1-5.5 days (Duki 2003).

\section{Early diagnosis}

The low attention from public health decision makers together with a lack of awareness among healthcare professionals and physicians of recommended procedures are the main reasons for the persistent insufficient approach to COPD in recent decades, even in most industrialized and advanced countries.

Despite the heavy impact of COPD in terms of morbidity, mortality, and total costs on populations worldwide, COPD still represents a disease condition largely under-diagnosed during the earliest stages and under-estimated in the more severe phases (Rennard et al 2002; Dal Negro et al 2003a; European Lung White Book 2003).

The still insufficient use of diagnostic, staging, and monitoring procedures (such as spirometrical tests) is confirmed by the still negligible proportion of resources used for diagnosis and investigation (only 5\%-6\% of total healthcare direct costs for COPD) (Britton 2003; Dal Negro et al 2008).

Under-recognition is particularly damaging in terms of both incidence and morbidity of COPD, also contributing to the consequent unawareness and to inappropriate management of the disease (Rennard et al 2002; European Lung White Book 2003; Dal Negro et al 2003a).

Even though lung function outcomes (ie, $\mathrm{FEV}_{1}$ changes) do not mirror the severity of respiratory symptoms and clinical changes perceived by patients in real life (see above), 
the disease staging needs these lung function measures. In practice, all interventional strategies aimed at COPD control should be accompanied by lung function measures in order to provide objective indices for assessing and monitoring all events and outcomes. When widely adopted in most patients in whom COPD is suspected, this approach will fit international guidelines better.

One study aimed to assess the cost-effectiveness of early diagnosis of COPD showed that the cost for each diagnosed case (by means of spirometry, reversibility, and bronchial hyperreactivity measures) was US\$564, lower than the cost of screening programs for different diseases (van den Boom et al 1998). Obviously, a better knowledge of the disease would induce an immediate higher use of healthcare resources following the screening program, but the net results of this approach should not be assessed in the short term: the potential long-term advantages of early interventions should be taken into account, and the corresponding costs diluted in a long-term vision for interventional strategies.

\section{Reduction of hospital costs}

Data that permit an estimate of such costs should ideally be produced to reflect faithfully the true burden of COPD and to provide fully credible data to health care institutions.

From this arises the importance of observational studies and modeling on health outcomes, aimed not only at reducing costs but also at improving the management of COPD and optimizing the use of resources.

Further to prevention and early diagnosis, the health care organization is another cornerstone for planning an effective strategy against COPD.

Patients, health institutions, and society value highly hospital admissions and hospital stay. However there is a worldwide tendency to reduce hospitalizations, and in all industrialized countries, health care policy is aimed at reducing hospital admissions and their duration for acute diseases. But hospital admission still represents an opportunity for the vast majority of more severe cases, and for older patients, particularly during the last few years of their life (Andersson et al 2006), to face their own acute problems, and offers other possibilities for assistance scarcely or only anecdotally noted (such as domiciliary hospitalization, telemedicine). In particular, it should be taken into account that the most expensive $20 \%$ of COPD patients (likely the most severe) account for $74 \%$ of total health-care costs of the disease (Strassels et al 2001). However, it should be taken into account that patients with poor prognosis make abundant use of hospital services (Kinnunen et al 2006).
The results of domiciliary treatment of COPD are still debated and depend on several variables, such as a country's health care model; the clinical severity of patients admitted; and the organizational pattern of home assistance (Bergner et al 1998; Jones et al 1999). Data from these studies proved that the economic advantages can be negligible when all indirect costs (due to both the patient's and family's involvement) are considered. Other experiences produced more encouraging data particularly in terms of efficacy and duration of treatments, re-admissions in the 60 days following the patient's discharge, and deaths (Cotton et al 2000; Gravil et al 1998), with a reduction of direct costs of $£ 850$ (Cotton et al 2000) and by 38\% (MacIntyre et al 2002) per patient domiciliary treated. However, all these studies were carried out on small samples of patients and produced data that cannot be generalized.

Telemedicine has also been used in the past decade in several countries for the domiciliary management of chronic respiratory patients. Even though some aspects are still debated (such as the regulatory aspects of responsibilities), the clinical convenience of this model of assistance and the optimization of outcomes (both clinical and economic) were proved in more severe stages of COPD (Micheletto et al 1994; Dal Negro 2000; Agha et al 2002). In particular, in severe patients treated with long-term oxygen and home assisted for an average period of 6 years, telemetric management dramatically reduced direct costs (such as number of hospitalizations and their duration, healthcare resources, and drug use) and indirect costs (such as work days off for still-working subjects), starting in the first year of remote assistance at home (Micheletto et al 1994; Dal Negro 2000; Ravasio et al 2005). Moreover, morbidity and mortality due to infectious events also dropped significantly, so contributing to a further optimization of clinical (symptom relief, health status, and quality of life) and economic outcomes (Micheletto and Dal Negro 2005). The cost-effectiveness of this particular telemetric approach has been confirmed in the last two decades, thus stimulating the interest of decision makers and healthcare institutions in several countries. Evidently, the keystone for the perfect functioning of any telemetric model is perfect organization among all actors involved in the model, such as the institutional healthcare environment, medical stuff, nurses, technological partners, and families of severe COPD patients, which are all responsible for results and outcomes optimization. A quite recent study further confirmed the economic convenience of home telehealth programs for chronically ill patients, in which patient outcomes (health status and morbidity) were improved at a lower cost (Finkelstein et al 2006). 


\section{Treatment of disability}

Pulmonary rehabilitation has been defined as a multidisciplinary program of care for patients with chronic respiratory impairment that is individually tailored and designed to optimize physical and social performance, and autonomy.

COPD is a disabling disease and the relevance of physical rehabilitation for improving patients' health status in all stages of the disease is now well accepted (Pauwels et al 2001).

In recent years, specific studies proved that long-term rehabilitative programs significantly reduce hospital admissions and COPD exacerbations (Foglio et al 1999, 2001; Griffiths et al 2000). Furthermore, a controlled randomized study confirmed that a 2-month course of physical rehabilitation significantly reduces hospitalizations with a shorter hospital stay, and number of domiciliary medical visits in the year following rehabilitation (Griffiths et al 2000).

The cost-effectiveness of rehabilitation in COPD was also proved and it was assessed that the US $\$ 23,000$ needed per year of good quality life (QALY) is much lower than that for a coronary by-pass or for mammographic screening programs (Toevs et al 1984; Kaplan and Ries 1996). Moreover, when rehabilitation was added to other interventional programs for COPD control, the savings in terms of therapeutic resources was $£ 152$ (Griffiths et al 2001).

Hospital or domiciliary rehabilitation likely lead to different long-term results, even if a recent paper proved that a short hospital rehabilitative course of 12 sessions concentrated over 3 weeks gives the same results as a longer rehabilitative course of $<8$ weeks carried out in the outpatients' department (Clini et al 2001).

From a general point of view, physical rehabilitation represents world wide an intervention capable of affecting significantly the major COPD outcomes, such as those from both a patient (such as dyspnea and symptom relief, daily activities, quality of life, and disability) and a healthcare institution perspective (Tinlelman et al 2005).

\section{Pharmacological treatments}

According to the ATS/ERS definition, COPD is a preventable and treatable disease state characterized by airflow limitation that is not fully reversible (Celli and MacNee 2004). The old views of COPD were magically deleted by this definition and it was then no longer regarded as an orphan condition without any opportunity for control.

By means of this consensus document, it was stated that even though changes in airway patency still represent the first-line and widely used indicator (ie, $\mathrm{FEV}_{1}$ ) for assessing efficacy and effectiveness of treatments, other indices should be regarded as much more suitable and reliable criteria for such a multifactorial disease as COPD. As previously mentioned, changes in $\mathrm{FEV}_{1}$ following bronchodilators can be small but they are often accompanied by larger changes in lung volumes, which contribute to a reduction in perceived breathlessness.

Outcomes other than only basal and post-bronchodilator airway obstruction can then be collected and monitored with the aim of providing more reliable criteria for assessing and comparing the therapeutic convenience of different pharmacological interventions or strategies. In other words, while spirometric classification of COPD has proved useful in predicting outcomes such as health status and mortality, other indicators, such as dyspnea, BMI $\left(<21 \mathrm{~kg} / \mathrm{m}^{2}\right)$, and exercise capacity, should be introduced for a better and much suitable detection of COPD impact (Celli and MacNee 2004).

According to GOLD guidelines and in order to optimize outcomes, the pharmacological approach to COPD is progressively increasing and in proportion to clinical severity.

In general terms, effective medications for COPD are available and all patients who are symptomatic should be submitted to a course of drug treatment. Medications currently available can reduce or abolish symptoms, increase exercise capacity, reduce the number and severity of exacerbations, and improve health status and quality of life, even though at present no treatment has been documented as being able to modify significantly the rate of decline in lung function.

Bronchodilators represent the most effective and safe pharmacological option for controlling COPD symptoms in the vast majority of patients: even if changes in spirometrical flows following short-acting $\beta_{2}$ agonists can be small, they are often accompanied by sensible changes in lung volumes which contribute to a significant reduction in perceived breathlessness. It has also been shown that combining different agents leads to a greater positive change in lung function and symptoms.

In general, both short-acting $\beta_{2}$ agonists and anticholinergics, when combined, have been proven to affect basal lung function much more than each single drug used alone, exercise tolerance, consumption of reliever drugs prn, quality of life, absenteeism, and exacerbations (Friedman et al 1999; Dahl et al 2001).

Regular treatment with long-acting $\beta_{2}$ agonists and/or anticholinergic bronchodilators were defined as more convenient and more effective by the last version of GOLD guidelines, even though they represent a more expensive choice (such as in terms of drug cost) than older molecules; their impact on several intermediate outcomes (such as, symptoms, 
rescue medications, increasing time between exacerbations, and health status) should nonetheless substantially reduce total COPD costs. It should also be emphasized that exacerbations requiring hospital admission induce a 3\%-4\% shortterm mortality, and that $50 \%$ of those hospitalized patients are re-admitted in the next 24 weeks (McCrory et al 2001). Furthermore, salmeterol was shown to induce a significant amelioration in quality of life in COPD patients when regularly treated (Jones 1997). Moreover, when compared with short-acting anticholinergics and placebo, tiotropium has been shown to improve health status, to reduce frequency of exacerbations, and to decrease hospital admissions (Casaburi et al 2002; Vicken et al 2002).

Long-acting bronchodilators $\left(\beta_{2}\right.$ adrenergics and tiotropium) have been shown to lead to a further optimization of major outcomes and to the minimization of resource consumption, probably because of better compliance and adherence to phamacological protocols of treatment. Despite the increase in direct costs derived from the higher prices of most recent drugs, the overall cost-of-illness is decreasing substantially, mainly due to a consistent drop in number of hospital admissions and number of visits to emergency departments, and reduced consumption of rescue treatments.

Despite a greater change in lung function (Zuwallack et al 2001), when theophylline (a weak bronchodilator, with a narrow therapeutic index) is added to long-acting bronchodilators the net effect on these outcomes did not change significantly despite a substantial increase in costs $(€ 350$ patient/year), which was mainly due to laboratory tests to check and monitor theophylline plasma levels periodically (Hilleman et al 2000).

Even though COPD has been defined as an inflammatory disease, the use of steroids in COPD is still debated mainly due to their inability to affect the progressive decline in lung function $\left(\mathrm{FEV}_{1}\right)$ (Pauwels et al 1999; Burge et al 2000; Lung Health Study Research Group 2000; D’Souza et al 2006). Nonetheless, GOLD guidelines suggest the regular use of steroids in advanced COPD patients in whom steroids were previously documented as effective in terms of symptom relief, lung function, and health status (Coyle and Lee 1998; Pauwels et al 2001). However, when severe patients are uncontrolled by regular treatments, adding inhaled corticosteroids to treatment represents a justifiable and common procedure. Even though the true effectiveness of inhaled steroids on major outcomes of COPD has still to be clarified, a few years ago a pivotal study carried out on a large institutional database pinpointed the role of inhaled steroids regularly used for at least some weeks per year in substantilally reducing number deaths (Soriano et al 2003). The value of inhaled corticosteroids in COPD (according to disease severity) was also investigated a few years ago by means of health economic models (Borg et al 2004), and particularly in elderly COPD patients (Schmier et al 2005), but the scientific community is still waiting for further data for definitive conclusions.

Health economic modeling to compare pharmacological maintenance strategies in COPD is not commonly used. As previously mentioned, health economic models were used to assess the value of inhaled corticosteroids in COPD according to disease severity (Sin et al 2004). A particular probabilistic model (such as the Markov model) was also employed for investigating the role of long-acting anticholinergics in patients with COPD over a long period of time (Borg et al 2004; Oostenbrink et al 2004; Spencer et al 2005).

As current practice guidelines for treating COPD recommend the use of combined inhaled corticosteroids and longacting bronchodilators in severe and very severe patients (GOLD stages III and IV), the value of this pharmacological option was also investigated by means of the same probabilistic model (Iannazzo et al 2005), in order to assess the economic and clinical impact of this recommendation, the affordability of its widespread application, as well as the relative pharmacoeconomic performance of the available options for severe and very severe COPD. Published data on the Italian COPD population were fitted in a disease progression model based on a Markov chain representing severity stages and death. Alternative therapeutic options (salmeterol/fluticasone $[\mathrm{S} / \mathrm{F}]$, formoterol/budesonide [F/B], salmeterol alone, $[\mathrm{S}]$, fluticasone alone $[\mathrm{F}]$, and control [C]) were represented as competing arms in a decision tree. Efficacy data from international trials were expressed in terms of risk reduction. Clinical parameters used were number of exacerbations and symptom-free days. Direct and indirect costs were considered and valued according to current prices and tariffs. Analyses were conducted from National Health Service, societal, and patient perspectives with time horizons of 1, 5, 10 years, and life-long. Mean survival of the cohort was 11.5 years. The $\mathrm{C}$ and $\mathrm{F}$ strategies are dominated (ie, were associated with worse outcomes and higher costs) by all alternatives. $\mathrm{S} / \mathrm{F}$ and $\mathrm{F} / \mathrm{B}$ were the most effective strategies, with a slight clinical superiority of $\mathrm{S} / \mathrm{F}$, but they were also marginally more expensive than $\mathrm{S}$. Incremental cost/effectiveness of $\mathrm{S} / \mathrm{F}$ vs $S$ was $€ 679.5 /$ avoided exacerbation and $€ 3.3 /$ symptom-free day. The recommended use of combined inhaled corticosteroids and long-acting bronchodilators for severe and very severe COPD patients proved capable of improving clinical outcomes without increasing health care costs. 
In an observational study over a 36-month period, it was shown that when compared with both single components, corticosteroids and long-acting bronchodilator combination leads to a much better optimization of both life expectancy and costs, thus further confirming the cost-effectiveness of this pharmacological strategy (Gagnon et al 2005).

New pharmacoeconomic analyses are providing some new specific indices for assessing and representing more precisely the greater convenience of therapeutic choices. ICOR, the additional cost required to produce an additional unit of outcome, has been used in a recent study for defining a cost-effectiveness plane, which is now regarded as a much more complete way for assessing economic convenience between different pharmacological options (Drummond et al 1997).

As exacerbations represent one of the major intermediate outcomes of COPD management, and can affect quality of life (Seemungal et al 1998), several studies have focused on the therapeutic convenience of approaching this particular issue and assessed the corresponding pharmacoeconomic impact of different pharmacological strategies in the past few years.

Some pivotal controlled studies are suggesting the longterm use (usually 1 year) of combined inhaled $\beta_{2}$ adrenergics and steroids as particularly convenient in reducing both frequency and severity of COPD exacerbations when taken regularly (Calverley et al 2003b, c; Dal Negro et al 2003b; Szafransky et al 2003), concomitantly with improved quality of life and increased number of symptom-free days. As exacerbations represent the main cause of hospital admission for most severe COPD patients, this therapeutic performance led also to a substantial optimization of all economic outcomes. The appropriate and long-term use of combination therapies proved equally tolerated, effective, and cost-effective independently of the different molecules employed, their regular long-term use being the only variable that seems to play a relevant role in inducing positive results.

Also the regular long-term use of anti-cholinergics has been confirmed to affect positively the number of exacerbations and their severity (Dahl et al 2001).

COPD is a multifactorial disease characterized by several co-morbidities (mainly cardiovascular and metabolic) which contribute significantly to patient survival (Mannino 2002). The first pivotal, long-term, multicenter international trial carried out in order to investigate the effect of combination therapy on severe COPD patients' survival proved that the number of deaths (due to all causes) drop by $17.5 \%$ only following regular treatment for 3 years with $\beta_{2}$ adrenergics plus steroids, but not with a placebo or with each single component alone (Calverley et al 2006; Celli et al 2003). This extremely important outcome was obtained concomitantly with a substantial reduction in number of exacerbations (mild and severe exacerbations) and to the optimization of all other intermediate outcomes, such as improved lung function, symptom relief, health status, and improvement in quality of life.

The key message from all these most recent controlled studies carried out on large number of patients worldwide is that the prompt diagnosis of disease and disease exacerbations (Wedzicha and Wilkinson 2006), together with the appropriate and long-term therapeutic approach to COPD patients, represent the only strategy to optimize all outcomes related to the disease and to reduce substantially the impact of COPD on patients, healthcare institutions, and society.

At present, the under-diagnosis, the under-consideration, and the under-treatment of COPD still represent the main cause of ever increasing disease-induced direct and indirect costs; treatment failure due to inappropriate or insufficient therapeutic approach is the main cause of growing COPD morbidity and mortality.

Despite the number of functional, clinical, and humanistic indicators presently used for assessing and monitoring the effects of interventional strategies against COPD (Jones and Agusti 2006), newer markers and more reliable outcomes should be sought in the near future in order to provide more precise and optimal economic outcomes for COPD management.

\section{References}

Agha Z, Schapira RM, Maker AH. 2002. Cost-effectivenenss of telemedicine for the delivery of outpatient pulmonary care to a rural population. Telemed J E Health, 8:281-91.

Andersson FL, Svensson K, Gerhardsson de Verdier M. 2006. Hospital use for COPD patients during the last few years of their life. Respir Med, 100:1436-41.

Anto JM, Vermeire P, Vestbo J, et al. 2001. Epidemiology of chronic obstructive pulmonary disease. Eur Respir J, 17:982-94.

Bergner M, Hudson ID, Conrad DA, et al. 1998. The cost and efficacy of home care for patients with chronic lung disease. Med Care, 26:566-79.

Borg S, Ericsson A, Wedzicha J, et al. 2004. A computer simulation model of the natural history and economic impact of chronic obstructive pulmonary disease. Value Health, 7:153-67.

Britton M. 2003 The burden of COPD in the U.K.: results from the confronting COPD survey. Respir Med, 97(Suppl C):S71-9.

Burge PS, Calverly PM, Jones PW, et al. 2000. Randomised, double blind, placebo controlled study of fluticasone propionate in patients with moderate to severe chronic obstructive pulmonary disease: the ISOLDE trial. BMJ, 320:1297-303.

Calverly PM, Boonsawat W, Cseke Z, et al. 2003c. Maintenace therapy with budesonide and formoterol in chronic obstructive pulmonary disease. Eur Respir J, 22:912-19.

Calverley PM, Burge PS, Spencer S, et al. 2003a. Bronchodilator reversibility testing in chronic obstructive pulmonary disease. Thorax, 58:659-64. 
Calverley PMA, Ferguson GT, Anderson JA, et al. 2006. The TORCH (TOwards a Revolution in COPD Health) study:salmeterol/fluticasone propionate (SFC) improves survival in COPD over three years. Eur Respir J, 28(Suppl 50):34S.

Calverley P, Pauwels R, Vesto J, et al. 2003b. Combination salmeterol and fluticasone in the treatment of chronic obstructive pulmonary disease: a randomized controlled trial. Lancet, 361:449-56.

Casaburi R, Mahler DA, Jones PW, et al. 2002. A long-term evaluation of once daily inhaled ipratropium in chronic obstructive pulmonary disease. Eur Respir J, 19:217-24.

Celli B, Calverley PMA, Anderson JA, et al. 2006. The Towards a Revolution in COPD Health (TORCH) study: fluticasone propionate/ salmeterol reduces the rate of exacerbations over 3 years. Chest, 130 (Suppl 4):177S.

Celli BR, MacNee W, and committee members. 2004. Standards for the diagnosis and treatment of patients with COPD: a summary of the ATS/ERS position paper. Eur Respir J, 23:932-46.

Chan-Yeung M, Ait-Khaled N, White N, et al. 2004. The burden and impact of COPD in Asia and Africa. Int J Tuberc Lung Dis, 8:1-14.

Chapman KR et al. 2006. Epidemiology and costs of chronic obstructive pulmonary disease. Eur Respir J, 27:188-207.

Clini E, Foglio K, Bianchi L, et al. 2001. In-hospital shrt-term training program for patients with chronic airway obstruction. Chest, 120:1500-5.

Cotton MM, Bucknall CE, Dagg KD, et al. 2000. Early discharge for patients with exacerbations of chronic obstructive pulmonary disease: a randomized controlled trial. Thorax, 55:902-6.

Coyle D, Lee KM. 1998. The problem of protocol driven costs in pharmacoeconomic analysis. Pharmacoeconomics, 14:357-63.

D'Souza AO, Smith MJ, Miller LA, et al. 2006. An appraisal of pharmacoeconomic evidence of maintenance therapy for COPD. Chest, 129:1693-708.

Dahl R, Greehorst LA, Nowak D, et al. 2001. Inhaled formoterol dry powder versus ipratropium in chronic obstructive pulmonary disease. $\mathrm{Am} \mathrm{J}$ Respir Crit Care Med, 164:778-84.

Dal Negro RW. 2000. Long-term oxygen tele-home monitorino, the Italian perspective. Chest Companion Book. pp. 247-9.

Dal Negro R, Berto P, Tognella S, et al. 2002. Cost-of-illness of lung disease in the TriVeneto Region, Italy: the GOLD Study. Monaldi Arch Chest Dis, 57:1-7.

Dal Negro R, Rossi A, Cerveri I. 2003a. The burden of COPD in Italy:results from the Confronting COPD survey. Respir Med, 97:s43-50.

Dal Negro RW, Pomari C, Tognella S, et al. 2003b. Salmeterol and fluticasone $50 \mathrm{mcg} / 250 \mathrm{mcg}$ bid in combination provides a better long-term control than salmeterol $50 \mathrm{mcg}$ alone and placebo in COPD patients already treated with theophylline. Pulm Pharm Ther, 16:912-19.

Dal Negro RW, Tognella S, Tosatto R, et al. 2008. Costs of chronic obstructive pulmonary disease (COPD) in Italy: The SIRIO study (Social Impact of Respiratory Integrated Outcomes). Respir Med, 102:92-101.

Detournay B, Pribil C, Fournier M, et al. 2004. The SCPE study: health-acre consumption related to patients with chronic obstructive pulmonary disease in France. Value Health, 7:168-74.

Drummond M, et al. 1997. Collection and analysis of data. In Drummond M, O'Brien BJ, Stoddart GL, et al. eds. Methods for the economic evaluation of health care programmes. New York, NY: Oxford University Press. pp. 96-138.

Duki MI. 2003. Effect of air pollution on respiratory health in Indonesia and its economic cost. Arch Environ Health, 58:135-43.

European Lung White Book. 2003. European Respiratory Society/European Lung Foundation.

Feenstra TL, van Genugten MI, Hoognveen RT, et al. 2001. The impact of aging and smoking on the future burden of chronic obstructive pulmonary disease:a model analysis in The Netherlands. Am J Respir Crit Care Med, 164:590-6.

Finkelstein SM, Speedie SM, Potthoff S. 2006. Home telehealth improves clinical outcomes at lower cost for home healthcare. Telemed $J E$ Health, 12:128-36.
Foglio K, Bianchi I, Ambrosino N, et al. 2001. Is it really useful to repeat outpatient pulmonary rehabilitation programs in patients with chronic airway obstruction? A 2-year controlled study. Chest, 119:1696-704.

Foglio K, Bianchi I, Bruletti G, et al. 1999. Long-term effectiveness of pulmonary rehabilitation in patients with chronic airway obstruction. Eur Respir J, 13:125-32.

Friedman M, Serby CW, Menjoge SS, et al. 1999. Pharmacoeconomic evaluation of a combination of ipratropium plus albuterol compared with ipratropium alone and albuterol alone in COPD. Chest, 115:635-41.

Gagnon YM, Levy AR, Spencer MD, et al. 2005. Economic evaluation of treating chronic obstructive pulmonary disease with inhaled corticosteroids and long-acting beta2-agonists in a health maintenance organization. Respir Med, 99:1534-45.

Global Initiative for Chronic Obstructive Lung Disease. 2004. Global Strategy for the Diagnosis, Management and Prevention of Chronic Obstructive Pulmonary Disease. Updated 2004 Executive Summary. Based on April 1998 NHLBI/WHO Workshop.

Godfredsen NS, Vestbo J, Osler M, et al. 2002b. Risk of hospital admission and reduction:a Danish population study. Thorax, 57:967-72.

Godtfredsen NS, Holst C, Prescott E, et al. 2002a. Smoking reduction, smoking cessation, and mortality:a 16-year follow-up of 19,732 men and women from the Copenhagen Center for Prospective Population Studies. Am J Epidemiol, 156:994-1001.

GOLD Guidelines. 2003. Date accessed: December 2, 2005. URL: www. goldcopd.com.

Golmohammadi K, Jakobs P. 2004. Cost-effectiveness of inhaled corticosteroids for chronic obstructive pulmonary disease according to disease severity. Am J Med, 116:325-31.

Gravil JH, Al-Rawas OA, Cotton MM, et al. 1998. Home treatment of exacerbations of chronic obstructive pulmonary disease by an acute respiratory assessment service. Lancet, 351:1853-5.

Griffiths TI, Burr ML, Campbell IA, et al. 2000. Results at 1 year of outpatient multidisciplinary pulmonary rehabilitation: a randomized controlled trial. Lancet, 355:362-8.

Griffiths TL, Phillips CJ, Davies S, et al. 2001. Cost-effectiveness of an outpatient multidisciplinary pulmonary rehabilitation programme. Thorax, 56:779-84.

Halbert RJ, Isonaka S, Georg D, et al. 2003. Interpreting COPD prevalence estimates: what is the true burden of disease? Chest, 123:1684-92.

Halpin DM. 2006. Health economics of obstructive pulmonary disease. Proc Am Thorac Soc, 3:227-33.

Hilleman DE, Dewan N, Malesker M, et al. 2000. Pharmacoeconomic evaluation of COPD. Chest, 118:1278-85.

Iannazzo S, Pradelli L, Dal Negro RW, et al. 2005. Analisi di costo efficacia nella terapia della BPCO. Farmacoeconomia, 6:277-87.

Jacobson L, Hertzman P, Lofdahl CG, et al. 2000. The economic impact of asthma and chronic obstructive pulmonary disease (COPD) in Sweden in 1880 and 1991. Resp Med, 94:247-55.

Jones PW. 1997. Quality of life changes in COPD patients treated with salmeterol. Am J Respir Crit Care Med, 155:1283-9.

Jones PW, Agusti AG. 2006. Outcomes and markers in the assessment of chronic obstructive pulmonary disease. Eur Respir J, 27:822-32.

Jones J, Wilson A, Parker H, et al. 1999. Economic evaluation of hospital at home versus hospital care:cost minimization analysis of data from randomised controlled trial. $B M J, 319: 1547-50$.

Kaplan RM, Ries AL. 1996. Cost effectiveness of pulmonary rehabilitation. In Fishman AP Ed.:Pulmonary Rehabilitation. New York, Basel, Hong Kong: Marcel Dekker. pp. 379-98.

Kinnunen T, Saynajakangas O, Keistinen T. 2006. The COPD-induced hospitalization burden from first admission to death. Respir Med. in press.

Lee TA. Sullivan ST, Buist AS, et al. 2006. Estimating the future economic burden of COPD. ATS Procedings, 3:A598

Leigh JP, Romano PS, Schenker MB, et al. 2002. Costs of occupational COPD and asthma. Chest, 121:264-72.

Lopez AD, Murray CC. 1998. The global burden of disease, 1990-2020. Nat Med, 4:1241-3. 
MacIntyre CR, Ruth D, Ansari Z. 2002. Hospital in the home is cost saving for appropriately selected patients: a comparison with in-hospital care. Int J Qual Health Care, 14:285-93.

Mannino DM. 2002. COPD: epidemiology, prevalence, morbidity and mortality, and disease heterrogeneity. Chest, 121(Suppl 5):121s-6s.

Masa JF, Sobradillo V, Villasante C, et al. 2004. Costs of chronic obstructive pulmonary disease in Spain:estimation from a population-based study. Arch Bronconeumol, 40:72-9.

McCrory DC, Brown CD, Gelfand SE, et al. 2001. Management of acute exacerbations of COPD. A summary and appraisal of public evidence. Chest, 119:1190-209.

Micheletto C, Dal Negro RW. 2005. The additional value of telemedicine. In Dal Negro RW, Goldberg AI eds. Home long-term oxygen treatment in Italy. Complicating events in patients during LTOT. Springer. pp. $109-18$.

Micheletto C, Pomari C, Righetti P, et al. 1994. A two-year health economics survey on 61 subjects in telemetric LTOT: preliminary results. Eur Respir J, 7(Suppl 18):266.

Miller RM, George D, Halbert RJ. 2005. Improving the management of chronic obstructive pulmonary disease. J Health Qual, 27:42-7.

Minkoff NB. 2005. Analysis of the current care model of the COPD patient: a health outcomes assessment and economic evaluation. J Manag Care Pharm, 11:s3-7.

Miravittles M, Murio C, Tina Guerrero T, et al. 2002. Pharmacoeconomic evaluation of acute exacerbations of chronic bronchitis and COPD. Chest, 121:1449-55.

Murray CJ, Lopez AD. 1997. Alternative projections of mortality and disability by cause 1990-2020: Global Burden of Disease Study. Lancet, 349:1498-504.

National Heart, Lung, and Blood Institute. 2004. Morbidity and mortality 2004 chart book on cardiovascular, lung, and blood diseases. URL: http//www. nhlbi. nih. gov/ resources/docs /04_chtbk.pdf. Accessed Sept. 13, 2004.

Nishimura S, Zaher C. 2004. Cost impact of COPD in Japan:opportunities and challenges? Respirology, 9:466-73.

Ofman JJ, Badamgarav E, Henning JM, et al. 2004. Does disease management improve clinical and economic outcomes in patients with chronic diseases? A systematic review. Am J Med, 117:182-92.

Oostenbrink JB, Rutten von Molken MP, Al MJ, et al. 2004. One-year costeffectiveness of tiotropium versus ipatropiumto treat chronic obstructive pulmonary diseases. Eur Respir J, 23:241-9.

Pauwels RA, Buist AS, Calverley PM, et al. 2001. Global strategy for the diagnosis, management, and prevention of chronic obstructive pulmonary disease. NHLBI/WHO Global Initiative for Chronic Obstructive Lung Disease (GOLD) Workshop summary. Am J Respir Crit Care Med, 163:1256-76.

Pauwels RA, Lofdhal CG, Laitinen LA, et al. 1999. Long term treatment with inhaled budesonide in persons with mild chronic obstructive pulmonary disease who continue smoking. $N$ Engl J Med, 340:1948-53.

Peters J. et al. 1998. Economic burden of environmental tobacco smoke on Hong Kong families:scale and impact. J Epidemiol Community Health, 52:53-8.

Ramsey SD, Sullivan SD. 2004. Chronic obstructive pulmonary disease: is there a case for early intervention? Am J Med, 117(Suppl 12):3-10.

Ravasio R, Dal Negro RW, Lucioni C. 2005. Valutazione economica dei costi associati al trattamento di pazienti con ossigenoterapia di lungo termine con o senza teleossimetria. Farmacoecononia, 6:349-52.

Rennard S, Decramer M, Calverley PMA, et al. 2002. Impact of COPD in North America and Europe in 2000:subjects' perspective of Confronting COPD International Survey. Eur Respir J, 20:799-805.
Rutten van Molken MP, Feenstra TL. 2001. The burden of asthma and chronic obstructive pulmonary disease:data from The Netherlands. Pharmacoeconomics, 19(Suppl 2):1-6.

Schmier JK, Halpern MT, Jones ML. 2005. Effects of inhaled corticosteroids on mortality and hospitalization in elderly asthma and chronic obstructive pulmonary disease patients:appraising the evidence. Drugs Aging, 22:717-29.

Seemungal TA, Donaldson GC, Paul EA, et al. 1998. Effect of exacerbation on quality of life in patients with chronic obstructive pulmonary disease. Am J Respir Crit Care Med, 157:1418-22.

Silverman EK, Speizer FR. 1996. Risk factors for the development of chronic obstructive pulmonary disease. Med Clin North Am, 80:501-22.

Sin DD, Golmohammadi K, Jacobs P. 2004. Cost-effectiveness of inhaled corticosteroids for chronic obstructive pulmonary disease according to disease severity. Am J Med, 116:325-31.

Skrepnek GH, Skrepnek SV. 2004. Epidemiology, clinical, and economic burden, and natural history of chronic obstructive pulmonary disease and asthma. Am J Manag Care, 10:s219-38.

Soriano JB, Kiri VA, Pride NB, et al. 2003. Inhaled corticosteroids with/ without long-acting beta-agonists reduce the risk of rehospitalization and death in COPD patients. Am J Respir Med, 2:67-74.

Spencer M, Briggs, Grossman RF, et al. 2005. Development of an economic model to assess the cost effectiveness of treatment interventions for chronic obstructive pulmonary disease. Pharmacoeconomics, 23:619-37.

Strassels SA, Smith DH, Sullivan SD, et al. 2001. The costs of treating COPD in the United States. Chest, 119:344-52.

Sullivan SD, Ramsey SD, Lee TA. 2000. The economic burden of COPD. Chest, 117(Suppl 2):s5-9.

Szafransky W, Cukier A, Ramirez A, et al. 2003. Efficacy and safety of budesonide/formoterol in the management of chronic obstructive pulmonary disease. Eur Respir J, 21:74-81.

The Lung Health Study Research Group. 2000. Effect of inhaled triamcinolone on the decline in pulmonary function in chronic obstructive pulmonary disease. New Engl J Med, 343:1902-9.

Tinlelman D, Nordyke RJ, Isonaka S, et al. 2005. The impact of chronic obstructive pulmonary disease on long-term disability costs. J Manag Care Pharm, 11:25-32.

Toevs CD, Laplan RM, Atkin CJ. 1984. The costs and effects of behavioural programs in chronic obstructive pulmonary disease. Med Care, 22:1088-100.

Tynan Aj, Lane SJ. 2005. COPD: illness severity, resource utilization and cost. Ir Med J, 98:41-42, 44-45.

van den Boom G, van Schayck CP, van Mollen MP, et al. 1998. Active detection of chronic obstructive pulmonary disease and asthma in general population. Results and economic consequences of the DIMCA program. Am J Respir Crit Care Med, 158:1730-8.

Vicken W, Van Noord JA, Greefhorst AP, et al. 2002. Improved health outcomes in patients with COPD during 1 year treatment with tiotropium. Eur Respir J, 19:209-16.

Viegi G, Scognamiglio A, Baldacci S. et al. 2001. Epidemiology of chronic obstructive pulmonary disease. Respiration, 68:4-19.

Wedzicha JA, Wilkinson T. 2006. Impact of chronic obstructive pulmonary disease exacerbations on patients and payers. Proc Am Thorac Soc, 3:218-21.

World Health Organization Report. 1998. Life in the 21st Century. A vision for all. Geneva: World Health Organization.

Zuwallack RI, Mahler DA, Reilly D, et al. 2001, Salmeterol plus theophylline combination therapy in the treatment of COPD. Chest, 119:1661-70. 